\title{
Mortality as a key driver of the spatial distribution of aboveground biomass in Amazonian forest: results from a dynamic vegetation model
}

\author{
N. Delbart ${ }^{1, *}$, P. Ciais ${ }^{1}$, J. Chave ${ }^{2}$, N. Viovy ${ }^{1}$, Y. Malhi ${ }^{3}$, and T. Le Toan ${ }^{4}$ \\ ${ }^{1}$ Laboratoire des Sciences du Climat et de l'Environnement, UMR 8212 (CEA/CNRS/UVSQ), CEA-orme des Merisiers, \\ 91191 Gif-sur-Yvette, France \\ ${ }^{2}$ Laboratoire Evolution et Diversité Biologique, UMR 5174 (CNRS/Universite Paul Sabatier Toulouse 3), \\ 31062 Toulouse, France \\ ${ }^{3}$ Environmental Change Institute, School of Geography and the Environment, Oxford University, \\ South Parks Road, Oxford, UK \\ ${ }^{4}$ Centre d'Etudes Spatiales de la Biosphère, UMR 5126 (CNRS/CNES/IRD/UPS), Toulouse, France \\ *now at: Université Paris Diderot-Paris 7, Paris, France
}

Received: 7 April 2010 - Published in Biogeosciences Discuss.: 29 April 2010

Revised: 31 August 2010 - Accepted: 17 September 2010 - Published: 6 October 2010

\begin{abstract}
Dynamic Vegetation Models (DVMs) simulate energy, water and carbon fluxes between the ecosystem and the atmosphere, between the vegetation and the soil, and between plant organs. They also estimate the potential biomass of a forest in equilibrium having grown under a given climate and atmospheric $\mathrm{CO}_{2}$ level. In this study, we evaluate the Above Ground Woody Biomass (AGWB) and the above ground woody Net Primary Productivity $\left(\mathrm{NPP}_{\mathrm{AGW}}\right)$ simulated by the DVM ORCHIDEE across Amazonian forests, by comparing the simulation results to a large set of ground measurements ( 220 sites for biomass, 104 sites for $\mathrm{NPP}_{\mathrm{AGW}}$ ). We found that the $\mathrm{NPP}_{\mathrm{AGW}}$ is on average overestimated by $63 \%$. We also found that the fraction of biomass that is lost through mortality is $85 \%$ too high. These model biases nearly compensate each other to give an average simulated AGWB close to the ground measurement average. Nevertheless, the simulated AGWB spatial distribution differs significantly from the observations. Then, we analyse the discrepancies in biomass with regards to discrepancies in $\mathrm{NPP}_{\mathrm{AGW}}$ and those in the rate of mortality. When we correct for the error in $\mathrm{NPP}_{\mathrm{AGW}}$, the errors on the spatial variations in AGWB are exacerbated, showing clearly that a large part of the misrepresentation of biomass comes from a wrong modelling of mortality processes.
\end{abstract}

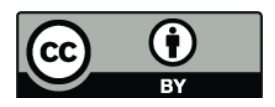

Correspondence to: N. Delbart (nicolas.delbart@1sce.ipsl.fr)
Previous studies showed that Amazonian forests with high productivity have a higher mortality rate than forests with lower productivity. We introduce this relationship, which results in strongly improved modelling of biomass and of its spatial variations. We discuss the possibility of modifying the mortality modelling in ORCHIDEE, and the opportunity to improve forest productivity modelling through the integration of biomass measurements, in particular from remote sensing.

\section{Introduction}

Tropical rainforests play a crucial but poorly known role in the global carbon cycle (Malhi and Grace, 2000). Deforestation and forest degradation contribute significantly to $\mathrm{CO}_{2}$ emissions to the atmosphere and are equivalent to about 1525\% of fossil fuel emissions (IPCC, 2007; Le Quéré et al., 2009). There is also strong evidence that undisturbed Amazonian and African tropical forests are currently a sink of carbon as they are accumulating more biomass (Stephens et al., 2007; Lewis et al., 2009a; Phillips et al., 2004; Lewis et al., 2009b; but see Jacobson, 2007). The mechanisms behind this carbon sink are subject to debate (Lewis et al., 2009; Körner, 2009): the carbon sink could be due to photosynthesis stimulation by increasing atmospheric $\mathrm{CO}_{2}$ rate (Phillips

Published by Copernicus Publications on behalf of the European Geosciences Union. 
et al., 2008; Gloor et al., 2009; Ciais et al., 2007) or to regeneration from earlier disturbance (Chave et al., 2008).

Diagnosing the carbon balance of tropical forests should rely on robust and repeated biomass estimations at large scale (Houghton, 2005; DeFries et al., 2001), but until recently maps of biomass stock in Amazonia retrieved from remote sensing, ground measurements or modelling showed striking differences (Houghton et al., 2001). Recently, advances combining field data, remote sensing techniques and innovative statistical methods have provided new insights on the distribution of Above Ground Woody Biomass (AGWB) in Amazonia (Malhi et al., 2006; Saatchi et al., 2007). In the future, dedicated remote sensing mission such as the BIOMASS mission (ESA, 2008; Le Toan et al., 2010) will provide consistent, global, and gridded AGWB dataset at spatial resolution of $100 \mathrm{~m}$, and will allow monitoring forest biomass lost due to disturbances and ensuing biomass increment. Consistency among recent maps suggests that the important regional variation in AGWB across Amazonia is not an artefact of measurement methods. Biomass distribution results from variations both in the tree allometry (Chave et al., 2005) and in wood density (Baker et al., 2004). It was also found that wood density, stem turnover, and productivity co-vary: the species with higher productivity have lower wood density and higher turnover rate. As a result, highest biomass stores are found for sites with lower turnover rates (Malhi et al., 2006).

Hypotheses about future carbon balance of Amazonian forests may be formulated using ecosystem models. One General Circulation Model coupled with a Dynamic Vegetation Models (DVM) predicted massive biomass loss during the 21 st century induced by reduced precipitation (Cox et al., 2001; Huntingford et al., 2008), in line with results from ecosystem manipulation experiments (Nepstad et al., 2007), although most climate models showed a more moderate intensification of seasonal drought (Malhi et al., 2009). DVMs compute energy, water and carbon fluxes between the ecosystem and the atmosphere, between the vegetation and the soil, and among plant organs. Most DVMs employ the concept of an "average plant" (but see e.g. Sato et al., 2007). For each average plant organ, a DVM simulates the carbon input (primary production allocated to the organ, translocation from another organ) and output (mortality or senescence, translocation to another organ). Under a constant climate and atmospheric $\mathrm{CO}_{2}$ level, a DVM reaches a steady-state equilibrium at which carbon inputs and outputs for each compartment balance each other on the long term. Depending on the study ecosystem, this equilibrium may be reached after several decades or centuries of simulation. Thus, DVMs simulate the potential climax biomass of a mature forests having grown under a given climate and atmospheric $\mathrm{CO}_{2}$ level.

By construction, any increase in primary productivity driven by climatic gradients or temporal changes (nitrogen deposition or $\mathrm{CO}_{2}$ increase) should result in an increase in biomass stock in a DVM. In a recent synthesis of ground based measurements of above ground biomass and net primary productivity allocated to the above ground parts of the plants, Keeling and Phillips (2007) showed that this premise is unrealistic. Specifically, they found that biomass stock is not linearly related to the productivity of tropical forests. Considering a range of sites, above-ground biomass shows a hump-shaped variation with productivity, as sites with high productivity (high carbon input) also have high turnover (high carbon output). To faithfully depict future trends in tropical forest biomass stocks, a DVM should correctly simulate both woody productivity and mortality fluxes. Some DVMs (e.g. Moorcroft et al., 2001) simulate temporal variations in mortality with forest regeneration (pioneer species have a high turnover rate) or drought that increases mortality. Still, such DVMs are unable to reproduce the regional variation of biomass in Amazonia, the highest biomass levels being obtained in North West Amazonia (Huntingford et al., 2008) whereas ground measurements show higher biomass level in central Amazonia or Guyana (Malhi et al., 2006). Thus, the initial conditions of the simulations predicting forest dieback with lower precipitation do not match the observations.

In this study, we evaluate the spatial variations in the biomass across the Amazon simulated by the ORCHIDEE DVM (Krinner et al., 2005). In ORCHIDEE, contrarily to other DVM (Sato et al., 2007), individuals are not represented and forests are considered as one average tree. Photosynthesised carbon remaining after plant maintenance and growth respiration computation is distributed to leaf, above ground wood, below ground wood, fine roots, fruits and reserves. Primary production and allocation of carbon are ruled by process-oriented schemes (Friedlingstein et al., 1999; Krinner et al., 2005). However, the loss of biomass through mortality is modelled very simply: every year a fixed fraction of the total carbon in wood is lost to litter. The mortality rate is defined as the inverse of the time of residence of carbon in wood, which is constant and prescribed. As there is no spatially explicit individual-based representation and as there is one carbon reservoir for trunks and branches, the time of residence of carbon in wood is equivalent to the average tree lifespan within this model framework.

Our first objective is to explore why DVMs fail to provide spatial gradients in AGWB under the current climatic conditions. Using a large set of AGWB observations, we show that the DVM ORCHIDEE outputs do not match empirical observations of regional variation in biomass over Amazonian forests. We analyse the discrepancies between model outputs and data with regard to discrepancies in carbon input to above ground wood and in the rate of mortality. We then test the idea of relating mortality to productivity as it is suggested by empirical evidence from the field data (Malhi et al., 2004). We discuss the consequences of this modification in predicting the spatial distribution of Amazonian biomass stores, and discuss possible improvements in the mortality module of DVMs. 
Our second objective is to explore the opportunity to improve forest productivity modelling through the integration of more accurate and spatially explicit observations on forest biomass stocks from satellite remote sensing. Here we discuss the use of future BIOMASS satellite data to constrain the carbon fluxes simulated by a DVM for mature forests.

\section{Material and methods}

\subsection{ORCHIDEE}

ORCHIDEE (Krinner et al., 2005) is a dynamic vegetation model. It is the result of the coupling of the SECHIBA landsurface scheme (Ducoudré et al., 1993), which is dedicated to surface energy and water balances, and the carbon and vegetation model STOMATE that calculates the carbon fluxes between the atmosphere, the vegetation and the soil. A third component is the vegetation dynamics module that calculates the spatial distribution of vegetation types, but it is not activated in our simulations as we prescribe the evergreen tropical vegetation type.

In this study we concentrate on the carbon dynamics sub-model STOMATE. In this model, Net Primary Production (NPP) is modelled as Gross Primary Production (GPP the amount of atmospheric carbon assimilated by photosynthesis) minus autrotrophic respiration $\left(R_{\mathrm{a}}\right)$. Both herbivore grazing of NPP (Keeling and Phillips, 2007), and Volatile Organic Compounds emission of $\mathrm{C}$ to the atmosphere (Kesselmeier et al., 1999) are ignored. NPP is allocated to several vegetation organs or compartments: above ground wood (AGW), below ground wood (BGW), fine roots, leaves, fruits and non structural reserve carbon stores. Organs lose carbon through mortality or senescence. The amount of biomass allocated to each organ is calculated from the following equation:

$\mathrm{NPP}_{\text {organ }}=f_{\text {alloc }- \text { organ }} \times \mathrm{NPP}$

with $\mathrm{NPP}_{\text {organ }}$ and NPP expressed in tonsC/ha/year, and $f_{\text {alloc-organ }}$ being a dimensionless fraction ranging from 0 to 1 .

At year $n$, AGWB is given (in tonsC/ha) by:

$\operatorname{AGWB}(n)=\operatorname{AGWB}(n-1)$

$+\mathrm{NPP}_{\mathrm{AGW}}(n-1)-$ mortality $(n-1)$

where mortality (in tonsC/ha/year) equals

mortality $(n-1)=\frac{\operatorname{AGWB}(n-1)}{t_{\text {residence }}}$,

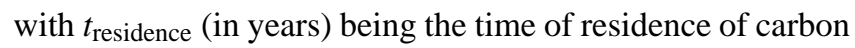
in wood. Note that the inverse of $t_{\text {residence }}$ is equal to the rate of mortality, i.e. the fraction of AGWB lost annually via mortality.
Then,

$\operatorname{AGWB}(n)=\operatorname{AGWB}(n-1) \times\left(1-\frac{1}{t_{\text {residence }}}\right)$

$+\operatorname{NPP}_{\mathrm{AGW}}(n-1)$.

Further details about the calculation of GPP, $R_{\mathrm{a}}$ and $f_{\text {alloc-organ }}$ are provided in Krinner et al. (2005). The value of $t_{\text {residence }}$ is prescribed and constant, set equal to 30 years for the tropical forest biome.

Our objective is to test these assumptions for undisturbed tropical forests. Thus we fixed the length of the simulations (Nyears) to 206 years (from 1801 to 2006), after checking that biomass stores equilibrate after 100 years.

\subsection{Field data}

Locations of ground observations are shown in Fig. 1.

\subsubsection{Biomass}

Ground-based above ground woody biomass measurements across 220 Amazonian forest sites were taken from Malhi et al. (2006). Some of these values were directly derived from individual tree diameter data using the allometric relationship of Baker et al. (2004) that incorporates wood density information. At other sites where only plot-level basal area information was available, AGWB estimates were derived from an allometric model that relates AGWB to basal area measurements and correcting for variations in wood density.

\subsubsection{Woody NPP and residence time}

Net primary production allocated to aboveground wood $\left(\mathrm{NPP}_{\mathrm{AGW}}\right)$ was estimated for 104 Amazonian forest sites by Malhi et al. (2004), based on dendrometric measurements conducted at the same site during two or more censuses. Only trees that reached the minimal census size of $10 \mathrm{~cm} \mathrm{dbh}$ were considered. Specifically, $\mathrm{NPP}_{\mathrm{AGW}}$ is the sum of two components: $1 /$ the individual tree biomass increment measured during the interval (inferred from the increment in basal area), plus $2 /$ the mass of trees recruited during the interval. A census-interval correction was introduced to account for trees that recruited, grew and died between censuses. The conversion from the basal area increment to biomass increment incorporates wood density estimates (Baker et al., 2004). As all sites did not have all necessary information, the correction due to wood density was determined empirically and applied to the available data (see details in Malhi et al., 2004). Malhi et al. (2004) also provided estimates of the residence time of carbon in tree woody biomass, defined by the ratio of $\mathrm{AGWB}$ to $\mathrm{NPP}_{\mathrm{AGW}}$.

\subsubsection{Leaf and fruit allocation}

Assuming that the forest canopy biomass is in equilibrium, NPP allocation to leaf and fruit was inferred from the 


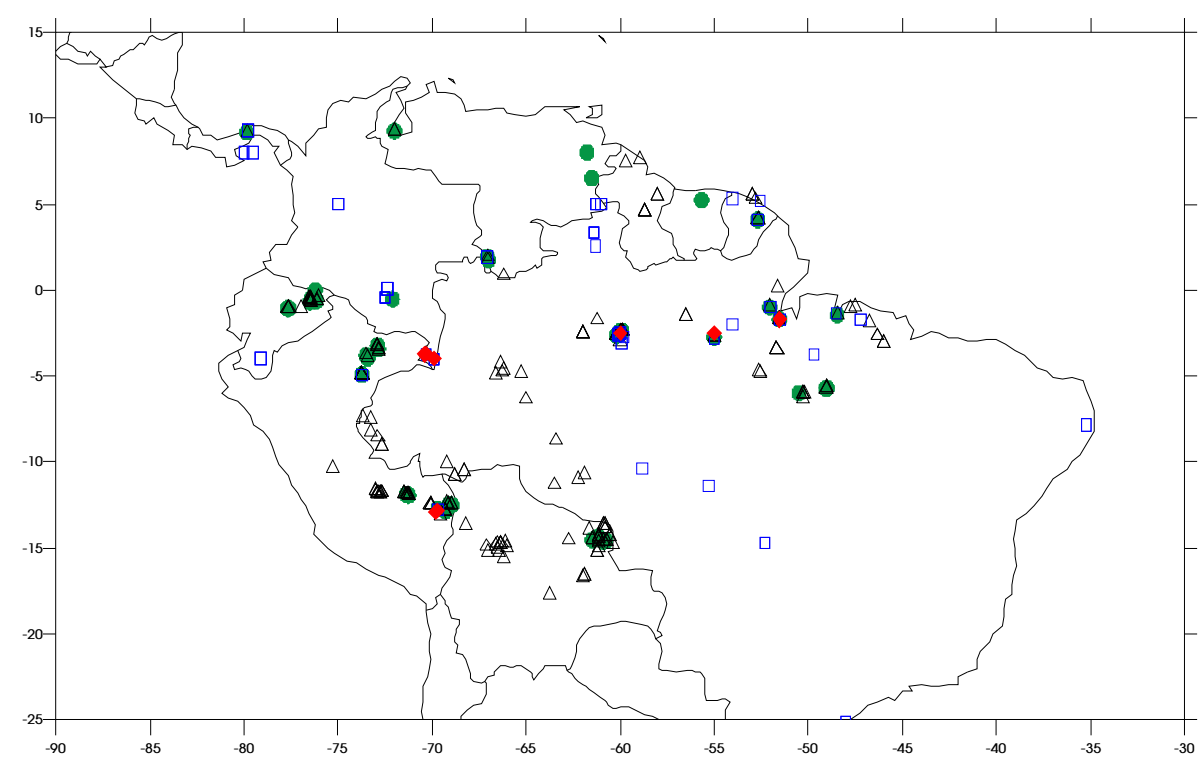

Fig. 1. Locations of ground observations. Black triangles: above ground woody biomass (Malhi et al., 2006). Green dots: above ground woody NPP (Malhi et al., 2004). Red diamonds: allocation fractions (Aragão et al., 2009). Blue squares: leaf and fruit allocation (Chave et al., 2010).

corresponding litterfall for 62 (leaf) and 51 (fruit) sites from Chave et al. (2010).

\subsubsection{Complete allocation pattern}

For ten sites ranging across lowland Amazonia, Aragão et al. (2009) estimated the total NPP and its partitioning among organs, including coarse and fine roots.

\subsection{Climatic data}

The climate dataset CRU-NCEP used for driving ORCHIDEE in this study is a combination of two existing datasets: the CRU TS.2.1 $0.5^{\circ} \times 0.5^{\circ}$, (Mitchell and Jones, 2005) monthly climatology covering the period 1901 to 2002 and the NCEP reanalysis $2.5^{\circ} \times 2.5^{\circ} 6 \mathrm{~h}$ time step beginning in 1948 and available in near real time (Kalnay et al., 1996). The processing (see appendix A) of CRU-NCEP aims at building a climatic dataset at $0.5^{\circ} \times 0.5^{\circ}$ spatial resolution, which keeps the diurnal and daily variability of NCEP and the monthly averages from CRU and which covers the period from 1901 until now. We used the climate data from years 1901-1950 repeatedly to simulate the forest growth over 1801-1900.

\subsection{Statistical analysis of ORCHIDEE results}

We ran ORCHIDEE at each site where ground measurements were available. We averaged the model outputs over the last 50 years of the simulations. We tested a shorter period (10 years) and showed that this had no impact on the interpretation of results. We analyzed the model output variables $\mathrm{AGWB}, \mathrm{NPP}, \mathrm{NPP}_{\text {organs }}$ separately in order to evaluate their mean values, their range and their spatial distribution. We used the statistical indicators as formulated in Willmott (1982).

\subsection{Impact of correcting $\mathrm{NPP}_{\mathrm{AGW}}$ while keeping a prescribed $t_{\text {residence }}$}

AGWB reaches equilibrium when $\mathrm{NPP}_{\mathrm{AGW}}$ and mortality compensate each other on average over several years. Equilibrium $\mathrm{AGWB}_{\max }$ is thus defined as :

$\mathrm{AGWB}_{\max }=\mathrm{NPP}_{\mathrm{AGW}} \times t_{\text {residence }}$

Here the objective is to determine the potential impact on the equilibrium $\mathrm{AGWB}_{\max }$ of improving the modelling of $\mathrm{NPP}_{\mathrm{AGW}}$ while preserving a prescribed mortality rate. For this purpose, we apply a multiplicative correction on $t_{\text {residence }}$ to make it equal to the average value from the ground measurements and we report this correction on $\mathrm{AGWB}_{\max }$ through Eq. (5). Then we test two types of correction on $\mathrm{NPP}_{\mathrm{AGW}}$, and evaluate their impact similarly through Eq. (5).

- First, we test the effect on $\mathrm{AGWB}_{\max }$ of removing the average bias on $\mathrm{NPP}_{\mathrm{AGW}}$ that was found from the statistical analysis. This allows testing of what would be the simulated $\mathrm{AGWB}_{\max }$ by adjusting the model parameters while keeping the same formulations.

- Second, we correct the site specific bias on $\mathrm{NPP}_{\mathrm{AGW}}$. This allows testing what would be the modelled $\mathrm{AGWB}_{\max }$ if $\mathrm{NPP}_{\mathrm{AGW}}$ and therefore all processes 
(a)

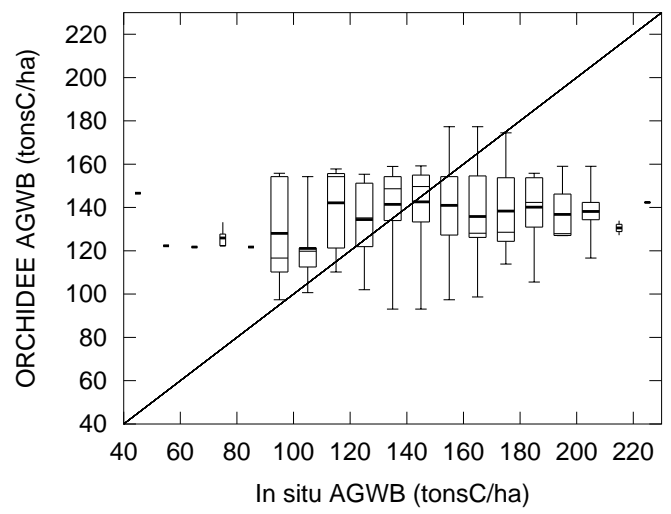

(c)

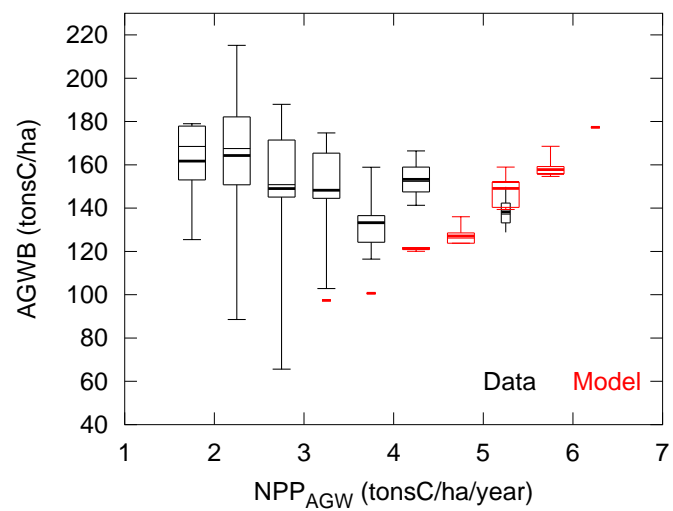

(b)

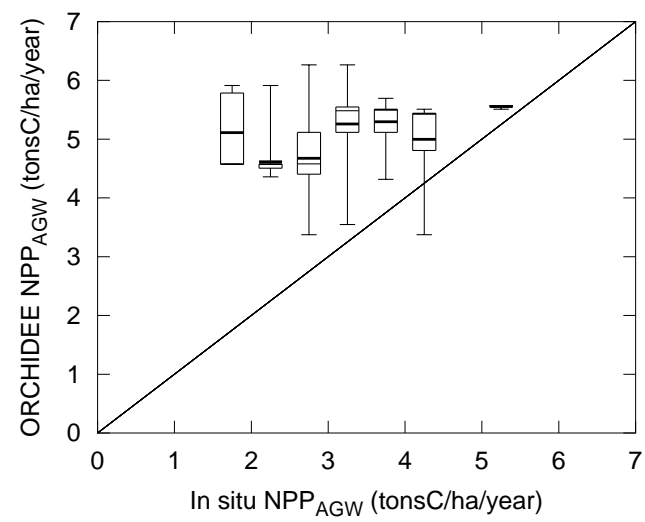

(d)

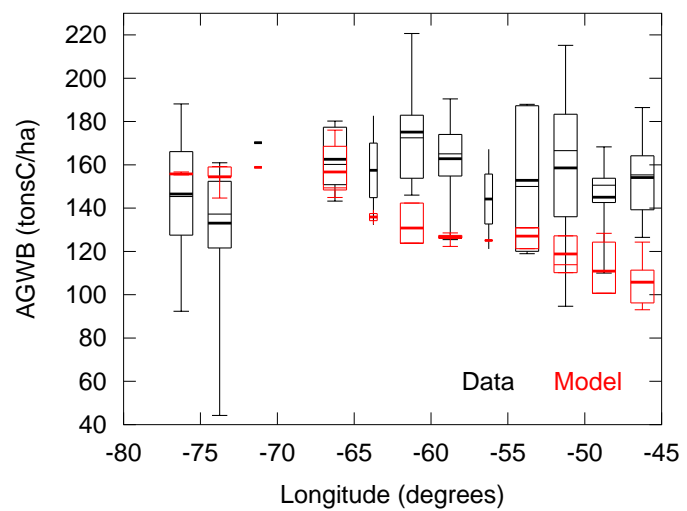

Fig. 2. Comparison of ORCHIDEE outputs with ground measurements. (a) Above ground woody biomass (AGWB); (b) Net Primary Production allocated to above ground wood ( $\left.\mathrm{NPP}_{\mathrm{AGW}}\right)$. (c) AGWB against $\mathrm{NPP}_{\mathrm{AGW}}$ from ORCHIDEE and ground measurements. (d) AGWB against longitude for latitude between $2^{\circ}$ north and $10^{\circ}$ south, from ORCHIDEE and ground measurements. Ground measurements are from Malhi et al. (2004, 2006). For each x-axis class: the vertical box represents the 25 and 75 percentiles; median in represented by a light line; average is represented by a bold line; whiskers extremities show the minimum and maximum values. In (c) and (d), red is for ORCHIDEE outputs and black for the ground measurements. The width of the box is reduced by half if less than 5 sites belong to a specific $\mathrm{x}$-axis class.

involved in photosynthesis, respiration and allocation were perfectly modelled. Remaining errors on $\mathrm{AGWB}_{\max }$ come from the mortality only, which in this case is defined from a constant $t_{\text {residence. }}$.

\subsection{Introducing a new mortality model}

$t_{\text {residence }}$ is given by Eq. (5) where $\mathrm{AGWB}_{\max }$ is the equilibrium AGWB. Across Amazonia, AGWB max $_{\text {max }}$ may change with variations in species distribution, climate and soil properties. Consequently, $\mathrm{AGWB}_{\max }$ could also spatially vary with ecosystem productivity such that:

$\mathrm{AGWB}_{\text {max }}=K \times \mathrm{NPP}_{\mathrm{AGW}}^{\alpha}$

Then $t_{\text {residence }}$ is obtained combining Eqs. (5) and (6) such that:

$t_{\text {residence }}=K \times \mathrm{NPP}_{\mathrm{AGW}}^{\alpha} \times \mathrm{NPP}_{\mathrm{AGW}}^{-1}$

$\alpha$ is the parameter that quantifies the variations in $\mathrm{AGWB}_{\max }$ with $\mathrm{NPP}_{\mathrm{AGW}}$. If $\mathrm{AGWB}_{\max }$ were not related to $\mathrm{NPP}_{\mathrm{AGW}}$, $\alpha$ would be equal to 0 . If $\mathrm{AGWB}_{\max }$ were proportional to $\mathrm{NPP}_{\mathrm{AGW}}$, the residence time would be fixed and $\alpha$ would be equal to 1 as in current ORCHIDEE parameterisation. If $\mathrm{AGWB}_{\max }$ decreased with $\mathrm{NPP}_{\mathrm{AGW}}, \alpha$ would be negative.

We evaluate $K$ and $\alpha$ by minimizing the average absolute difference between Eq. (7) and $t_{\text {residence }}$ from Malhi et al. (2004) for the $\mathrm{NPP}_{\mathrm{AGW}}$ values provided. We then apply Eq. (6) first to retrieve AGWB from ground measurements of $\mathrm{NPP}_{\mathrm{AGW}}$, second to retrieve $\mathrm{NPP}_{\mathrm{AGW}}$ from ground measurements of AGWB.

\section{Results}

\subsection{Evaluation of $\mathrm{AGWB}$ and $\mathrm{NPP}_{\mathrm{AGW}}$ simulated by ORCHIDEE}

Using ORCHIDEE's original parameters, we compared the model outputs with ground measurements. On average, 
Table 1. comparison of ORCHIDEE outputs (AGWB in tonsC/ha, NPP and NPP organs in tons C/ha/year) with ground measurements.

\begin{tabular}{lrrrrrrrrr}
\hline & \multicolumn{10}{c}{ NPP } \\
\hline Source of & Malhi et & Malhi et & Chave et & Chave et & Aragão et & Aragão et & Aragão et & Aragão et & Aragão et \\
ground data & al., 2006 & al., 2004 & al., 2010 & al., 2010 & al., 2009 & al., 2009 & al., 2009 & al., 2009 & al., 2009 \\
N & 220 & 100 & 62 & 51 & 10 & 10 & 10 & 10 & 10 \\
Obs Mean & 146.62 & 3.04 & 2.72 & 0.31 & 4.33 & 3.71 & 0.61 & 4.07 & 12.83 \\
Model Mean & 138.83 & 4.96 & 1.79 & 1.00 & 2.71 & 5.05 & 1.28 & 0.64 & 9.68 \\
RMSEs & 29.87 & 2.01 & 1.25 & 0.72 & 1.96 & 1.51 & 0.70 & 3.83 & 3.98 \\
RMSEu & 16.71 & 0.6 & 0.18 & 0.12 & 0.28 & 0.52 & 0.13 & 0.17 & 1.02 \\
RMSE & 34.23 & 2.1 & 1.26 & 0.73 & 1.98 & 1.60 & 0.71 & 3.84 & 4.11 \\
Slope & 0.07 & 0.25 & -0.01 & -0.01 & -0.01 & 0.10 & 0 & 0.04 & 0.01 \\
Intercept & 129.14 & 4.21 & 1.81 & 1.01 & 2.75 & 4.68 & 1.28 & 0.46 & 9.54 \\
$R$ & 0.12 & 0.32 & -0.04 & -0.01 & -0.04 & 0.14 & 0 & 0.42 & 0.03 \\
\hline
\end{tabular}

the simulated AGWB was close to the ground measurement (Fig. 2a), but the simulated $\mathrm{NPP}_{\mathrm{AGW}}$ was too high (Fig. 2b, Table 1). We found that to set the AGWB to realistic values, the overestimation of $\mathrm{NPP}_{\mathrm{AGW}}$ was balanced by an overestimation of the mortality rate $\left(3.33 \%\right.$ year $^{-1}$ given $t_{\text {residence }}=30$ years). This rate assumed in ORCHIDEE was higher than observed on average at the ground measurement sites $\left(1.8 \%\right.$ year $^{-1}$ as average $t_{\text {residence }}=55$ years $)$.

Despite overestimation of NPPAGW (Fig. 2, Table 1), total NPP (above and below ground) was found to be underestimated by $25 \%$ (Fig. 3a). This is explained by the fact that the allocation fraction to above ground wood was overestimated (Fig. 3b, Table 1) in the model compared to empirical data (Aragão et al., 2009; Chave et al., 2010). Allocation to below ground wood and to fruits was also overestimated (Fig. 3b-c, Table 1). By contrast, allocation to leaves was underestimated by $34 \%$, and allocation to fine roots by $84 \%$ in ORCHIDEE. For none of the tested parameters was there either a significant correlation or a linear regression slope that is close to 1 (Table 1), showing the model cannot reproduce the observed spatial patterns. The simulated $\mathrm{NPP}_{\text {leaf }}+$ fruit is equal to $0.54 \mathrm{NPP}_{\mathrm{AGW}}$, whereas the ground measurements indicate that $\mathrm{NPP}_{\text {leaf }}+$ fruit $=1.67 \mathrm{NPP}_{\mathrm{AGW}}$ on average.

The spatial distribution of AGWB across the Amazon forest, as modelled by ORCHIDEE's default parameters, differed from empirical observations, with a peak in AGWB in western Amazonia while ground measurements showed maximum AGWB in central Amazonia (Fig. 2d). Simulated AGWB increased with $\mathrm{NPP}_{\mathrm{AGW}}$ in contrast to direct observations (Fig. 2c). In the following we explore how much of this is explained by the fact that $t_{\text {residence }}$ is constant in ORCHIDEE, whereas the ground measurements data show that it decreases with increasing $\mathrm{NPP}_{\mathrm{AGW}}$.

\subsection{Impact on AGWB of correcting $\mathrm{NPP}_{\mathrm{AGW}}$ while keeping a constant mortality rate}

First, we corrected the model outputs by de-biasing NPP $\mathrm{AGW}_{\mathrm{AGW}}$ and fixing $t_{\text {residence }}$ as the average of the ground measurements. This correction corresponds to what could be implemented in ORCHIDEE by only adjusting model parameters while keeping the logic of a constant rate of mortality. The average AGWB was still close to the average of ground measurements. However, as the mortality was assumed to be constant, there was no improvement in the spatial distribution of AGWB compared to results in Fig. 2.

Second, we corrected the model outputs by forcing $\mathrm{NPP}_{\text {AGW }}$ with the data while keeping a constant $t_{\text {residence }}$ (55 years). This test allowed assessment of the error coming from $t_{\text {residence }}$ alone avoiding all errors on $\mathrm{NPP}_{\mathrm{AGW}}$ coming from the modelling of GPP, autotrophic respiration, allocation and uncertainties in the climatic data. The model-data discrepancies in spatial distribution of AGWB are then exacerbated (Fig. 4). This indicates that improving the modelling of GPP, respiration and allocation would lead to a worse distribution of AGWB in the absence of improvement in the mortality model.

\subsection{Impact on AGWB of a residence time in wood governed by $\mathbf{N P P}_{\mathrm{AGW}}$}

We found that the best empirical fit for the relationship between $t_{\text {residence }}$ and NPPAGW gave an $\alpha$ value of -0.32 (Figs. 5 and 6). This indicates a slight decrease in $\mathrm{AGWB}_{\max }$ with increasing $\mathrm{NPP}_{\mathrm{AGW}}$. This differs significantly from the value $\alpha=1$ that corresponds to the fixed mortality rate implemented in ORCHIDEE.

We then derived AGWB from Eq. (6) applied to the observations of $\mathrm{NPP}_{\mathrm{AGW}}$. The regional distribution of AGWB matched better to the observations than with a fixed mortality 
(a)

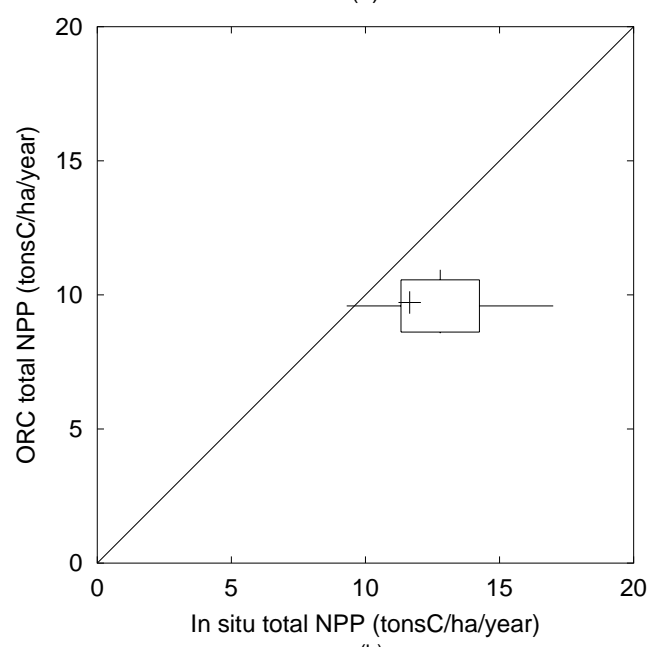

(b)
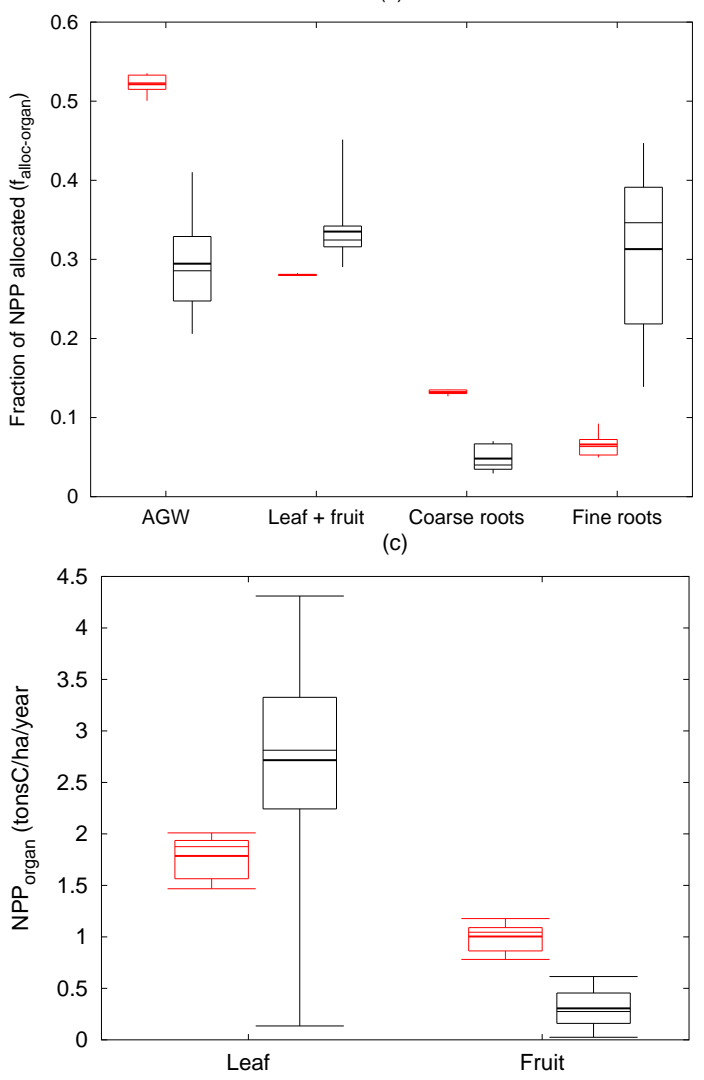

Fig. 3. Comparison of ORCHIDEE allocation with ground measurements. (a) Total Net Primary production; (b) Fraction of allocation of total NPP between organs ( $\left.f_{\text {alloc-organs }}\right)$ : Above Ground Wood (AGW), Leaf and fruit, Coarse Roots, Fine Roots (c) NPP allocated to leaf and fruit. Ground measurements for (a) and (b) are for 10 sites (Aragão et al., 2009). Ground measurements for (c) are based on litterfall measurements made for 62 sites (Chave et al., 2010). For each $x$-axis class: the vertical box represents the 25 and 75 percentiles; median in represented by a light line; average is represented by a bold line; whiskers extremities show the minimum and maximum values. In (b) and (c), red is for ORCHIDEE outputs and black for the ground measurements. rate (Fig. 7a and c). Hence, inferring $t_{\text {residence }}$ from $\mathrm{NPP}_{\mathrm{AGW}}$ resulted in a clear improvement for most of the sites in our dataset compared to the results presented in Fig. 4. Then, we derived $\mathrm{NPP}_{\mathrm{AGW}}$ from Eq. (6) applied to ground observations of $\mathrm{AGWB}$. The retrieved $\mathrm{NPP}_{\mathrm{AGW}}$ given AGWB became close to the observations (Fig. 7b and d). This shows that direct observations of AGWB may be used to constrain both $\mathrm{NPP}_{\mathrm{AGW}}$ and mortality in a DVM.

\section{Discussion and outlook}

Here we have demonstrated that the predictions of a DVM over the Amazon were incorrect in two major respects: the spatial distribution of AGWB did not match empirical observations, and the model assumed a too high turnover (both $\mathrm{NPP}_{\text {AGW }}$ and mortality). One major finding is that mortality rate is as important as net primary productivity and allocation in determining spatial gradients of above ground biomass, and that calculating the mortality as a constant fraction of the standing biomass prevents correct simulation of the spatial variations in above ground biomass. We then proposed an alternative strategy to account for these biases, which consists in relating mortality to $\mathrm{NPP}_{\mathrm{AGW}}$ on the basis of empirical evidence. This was effective to explain and reproduce partly the variations in AGWB of our dataset. We acknowledge this strategy should be tested over an independent dataset in the future, for example in central Africa.

Here, we calculated the mortality rate from a long term averaged $\mathrm{NPP}_{\mathrm{AGW}}$. This approach is probably only valid for the near-equilibrium context of mature, old growth forests. Two examples of where this equilibrium validity breaks down are given below. First, immediately after disturbance pioneer species with high turnover rate are favoured over late-successional ones. Thus, $t_{\text {residence }}$ should be smaller during the first years of simulation (Moorcroft et al., 2001). We expect that this should not affect steady-state biomass in a big leaf model such as ORCHIDEE but any forest that is currently recovering from a recent disturbance would not match perfectly with ORCHIDEE's predictions. Second, mortality increases as a consequence to drought stress (Nepstad et al., 2007). ORCHIDEE would simulate realistically the decrease in primary productivity in case of drought, but then Eq. (7) would lead to a decrease of the mortality rate, which is at odds with observations during the 2005 drought in the Amazon (Phillips et al., 2009). Then, the background mortality rate as modelled by Eq. (7), which appears from our results necessary to reproduced regional variations in AGWB, should be modulated by short term variations where mortality increases in case of adverse climate conditions in order to simulate temporal variations in AGWB. However, moderate and progressive decrease in precipitation may favour slow-growing species, with a low turnover rate and a high biomass. This point was ignored in previous Amazonian forest dieback simulations (Cox et al., 2004; Huntingford et al., 
(a)

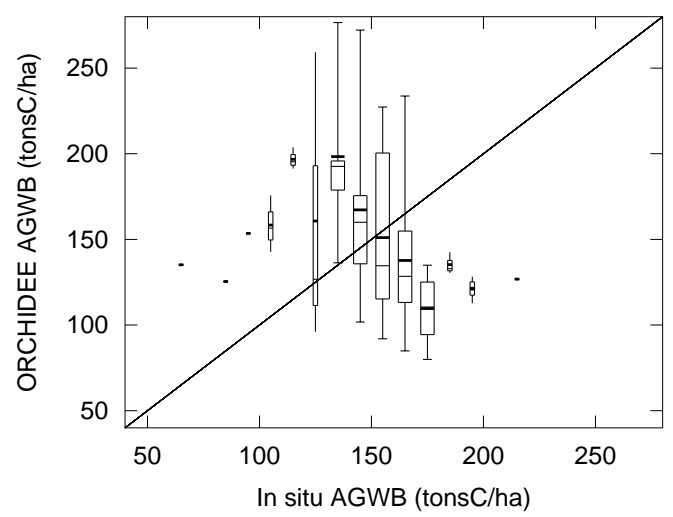

(c)

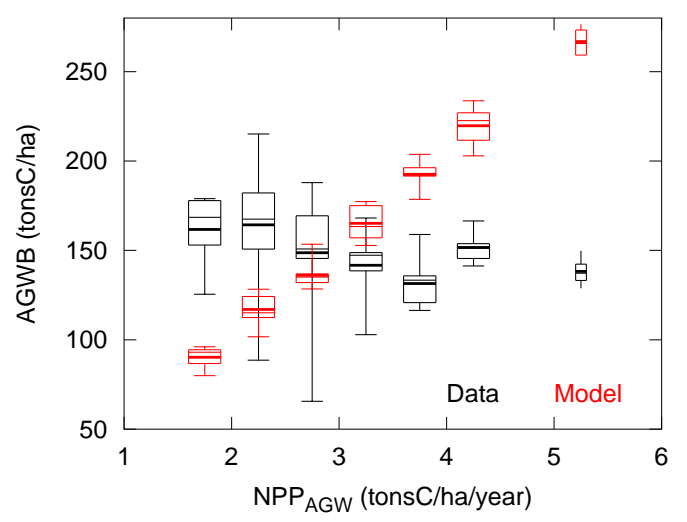

(b)

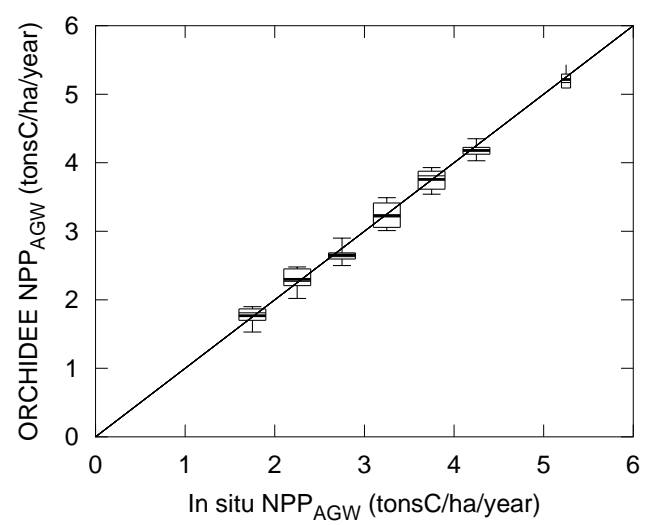

(d)

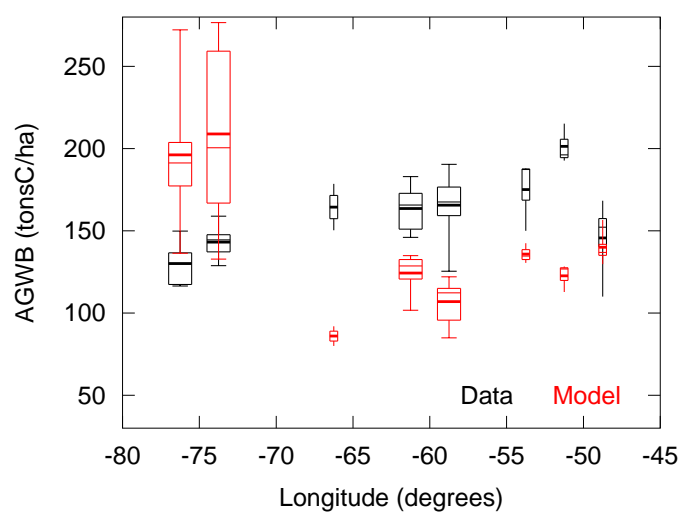

Fig. 4. Impact of forcing $\mathrm{NPP}_{\mathrm{AGW}}$ while keeping a constant mortality rate. Same legend than Fig. 2 except that we use the only 72 sites for which we have both ground measurements of $\mathrm{NPP}_{\mathrm{AGW}}$ and $\mathrm{AGWB}$.

2008) and could be modelled through Eq. (7). Nevertheless, as indicated by the observations of current biome spatial distribution (Malhi et al., 2009b), forest might be replaced by savannah if a large decrease in precipitation is experienced in the future in the Amazonian region.

Soil type is an important factor influencing $\mathrm{NPP}_{\mathrm{AGW}}$ and $t_{\text {residence}}$, as shown in Fig. 8. For example, forests with low $\mathrm{NPP}_{\mathrm{AGW}}$ and long $t_{\text {residence }}$ are favoured on older oxisol, whereas forests with high $\mathrm{NPP}_{\mathrm{AGW}}$ and short $t_{\text {residence }}$ are favoured on entisol. Based on ground measurements, Quesada et al. (2009) analysed the impact of soil properties on the mortality rate and on $\mathrm{NPP}_{\mathrm{AGW}}$. The mortality rate was found essentially influenced by the soil physical properties (topography, soil depth, structure), whereas $\mathrm{NPP}_{\mathrm{AGW}}$ was found primarily driven by fertility parameters, essentially phosphorus availability. The authors proposed that AGWB gradients can be explained by the ecosystem dynamics that is essentially driven by these soil properties. In Western Amazonia, poor soil physical properties (steep slope, shallow soils) favour high mortality rate, which favours earlysuccessional species with low wood density, whereas the high phosphorus availability induces higher $\mathrm{NPP}_{\mathrm{AGW}}$. In contrast, in central Amazonia, ecosystems are less dynamic, with better soil physical properties and lower fertility inducing respectively a lower mortality rate and a lower $\mathrm{NPP}_{\mathrm{AGW}}$. These two factors favour high wood density late-successional species, which ends up in higher AGWB. Equation (7) is in line with this explanation, as long as physical properties and fertility properties co-vary, which appears to be the case from the soil properties measurements reported in Quesada et al. (2010).

This strong influence of soil properties could be a key issue when modelling the future evolution of Amazonian forests under a climate change scenario, as soil type may limit the floristic composition change that we suggest to model through Eq. (7). However, this may also allow deriving maps of average $t_{\text {residence }}, \mathrm{NPP}_{\mathrm{AGW}}$ and thus AGWB from a soil type map.

A negative $\alpha$ value is consistent with the observation that slow growing forests as in central Amazonia have higher biomass than the fast growing forest as in Western Amazonia. However we cannot exclude that this apparent trend is affected by AGWB or $\mathrm{NPP}_{\mathrm{AGW}}$ measurement errors. If $\alpha$ were equal to zero, observed spatial variations of biomass would be independent of $\mathrm{NPP}_{\mathrm{AGW}}$. Then, this would mean that a DVM that would perfectly simulate carbon fluxes could at 


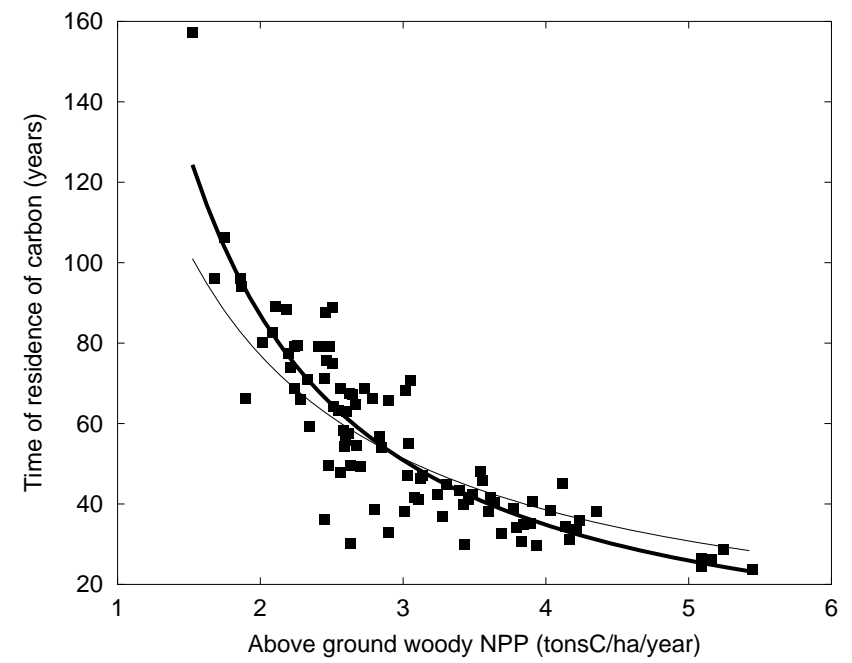

Fig. 5. time of residence of carbon in wood plotted versus

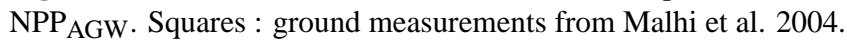
Bold line represents the best overall fit: $t_{\text {residence }}=217 \times \mathrm{NPP}_{\mathrm{AGW}}^{-1.32}$ (average absolute error: 7.30 years). Thin line represents the best fit for $\alpha=0: t_{\text {residence }}=154 \times \mathrm{NPP}_{\mathrm{AGW}}^{-1}$ (average absolute error : 8.6 years).

best give an AGWB that is spatially constant. In this case, biomass observations such as those from remote sensing could be used to estimate the $\mathrm{K}$ value (that would vary spatially independently from productivity) from Eq. (6) and then establish the relationship between mortality and $\mathrm{NPP}_{\mathrm{AGW}}$ from Eq. (7).

Our results show clearly that an $\alpha$ value of 1 , which is equivalent to the mortality calculation as it is done in ORCHIDEE, cannot explain the patterns in the data for the Amazonian forests. However, we found that keeping $\alpha$ equal to 1 does not prevent from reproducing spatial variations in AGWB for temperate and boreal forests biomes (not shown). In fact, as AGWB displays a hump-shaped variation with productivity when analysed over a range of biome types (Keeling and Phillips, 2007), it is unlikely that Eq. (7) applies to many other biomes, if any.

Implementing the new mortality computation requires that $\mathrm{NPP}_{\mathrm{AGW}}$ was modelled correctly. In ORCHIDEE, the priority in order to improve $\mathrm{NPP}_{\mathrm{AGW}}$ is to reduce the fraction of allocation to wood and distribute more carbon to leaves and fine roots. At high leaf area values, the DVM tends to allocate more carbon to wood in order to simulate the competition for light. However, under the current formulation of the allocation pattern, limitation by water or nutrients cannot be larger than the limitation by light for high leaf area index forests. Thus excessive carbon is allocated to wood for our evergreen tropical forest simulations. Model parameters should be adjusted to make the modelled allocation fractions to the different organs fall within the intervals given by the ground measurements. Non-linear effects in all fluxes

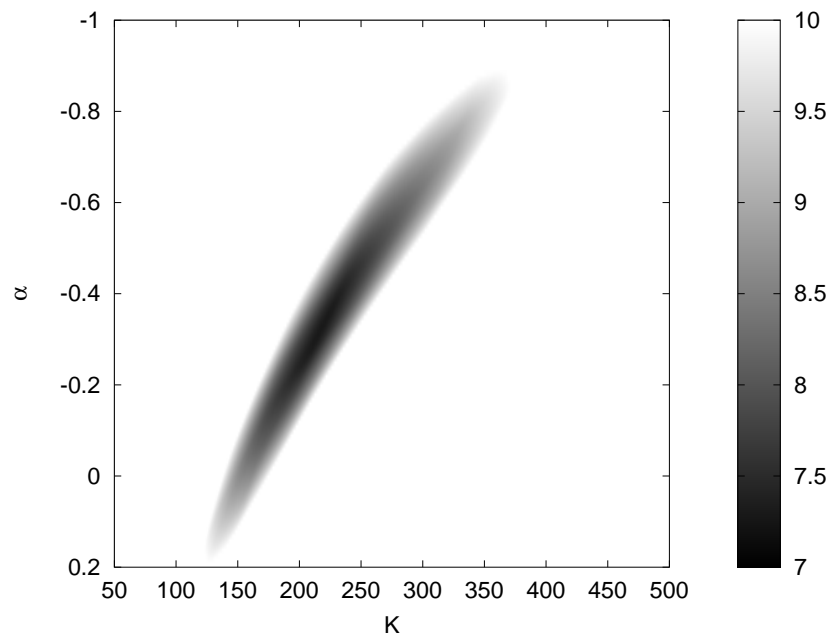

Fig. 6. Average absolute difference (years) between the computed $t_{\text {residence (from Eq. 7) and the ground measurements (Malhi et al., }}$ 2004) in a systematic exploration of the values of $\alpha$ and K.

must be expected as reallocating carbon to leaf and fine roots would stimulate photosynthesis and increasing water consumption by plants.

Thanks to the new formulation of mortality and because $\alpha$ was found different from zero, observations of AGWB can

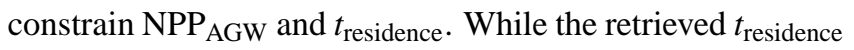
could be directly ingested by the model, correcting a DVM in order to reach the $\mathrm{NPP}_{\mathrm{AGW}}$ value retrieved from AGWB would not be trivial. It may involve a combination of possible corrections on parameterisation of photosynthesis, respiration and allocation. Then, adjusting the model should respect some constraints. First, Carbon Use Efficiency (CUE, which is the ratio of NPP to GPP) should remain close to the $0.30-0.35$ values derived from carbon cycling studies made in Amazonian mature forests (Malhi et al., 2009) as it is the case in current ORCHIDEE simulation $(\mathrm{CUE}=0.36)$. Second, carbon allocation should fall in the intervals given by the ground measurements. Then, because photosynthesis increases with nutrient availability (Davidson et al., 2004; Quesada et al., 2009), and because allocation does not seem to vary with it (Aragão et al., 2009), model photosynthesis parameters could be adjusted to reach the $\mathrm{NPP}_{\mathrm{AGW}}$ value derived from AGWB and Eq. (7). Forcing the model with biomass observations may thus help accounting implicitly for phosphorus limitation and other NPP controlling factors in a model like ORCHIDEE, or constrain the modelling of the nitrogen cycle in DVMs (Zaelhe et al., 2010). The use of biomass data to constraint the processes modelled in ORCHIDEE remains speculative, but the constraint on $\mathrm{NPP}_{\mathrm{AGW}}$ looks robust from our results (Fig. 7b and d). It is expected that biomass increments estimated by satellites such as the proposed BIOMASS mission (Le Toan et al., 2010) at several year interval could be used to infer $\mathrm{NPP}_{\mathrm{AGW}}$ for 
(a)

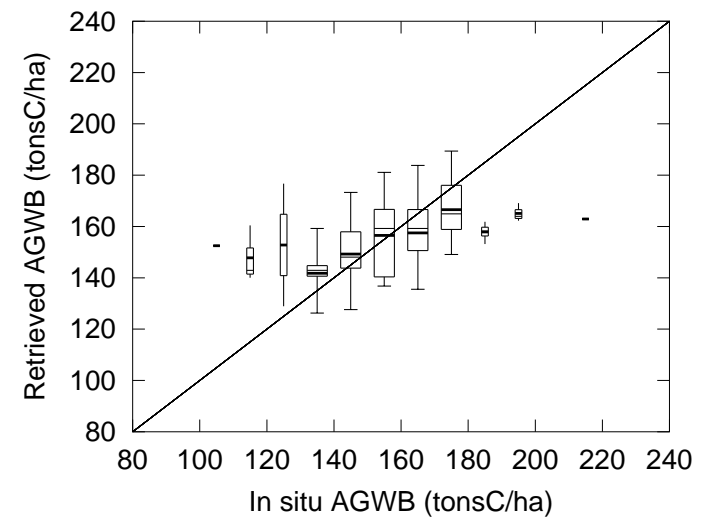

(c)

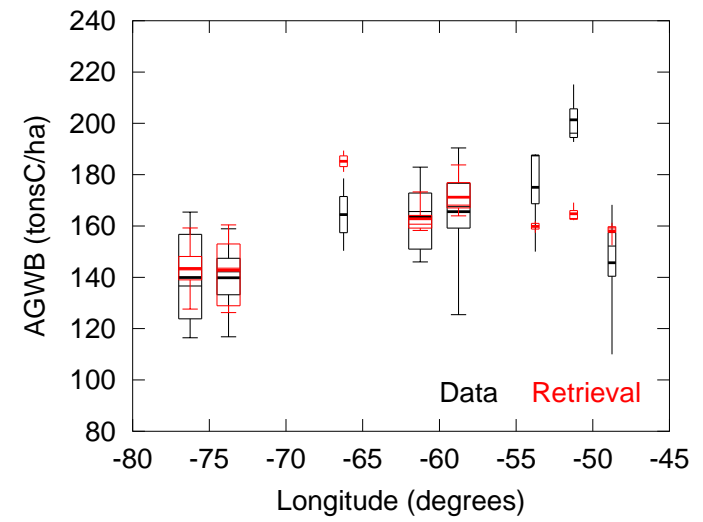

(b)

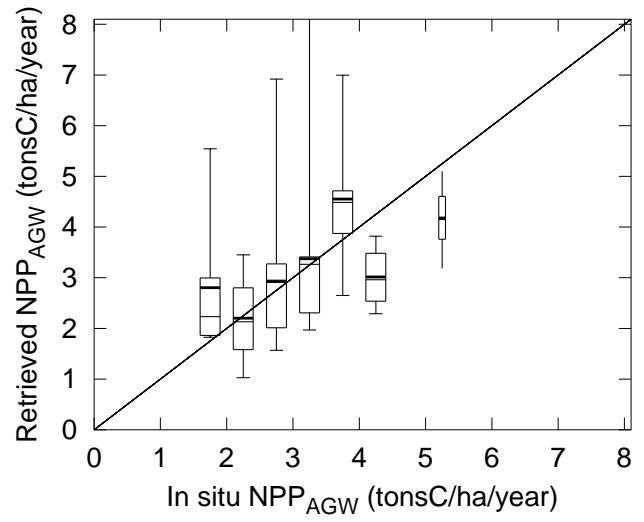

(d)

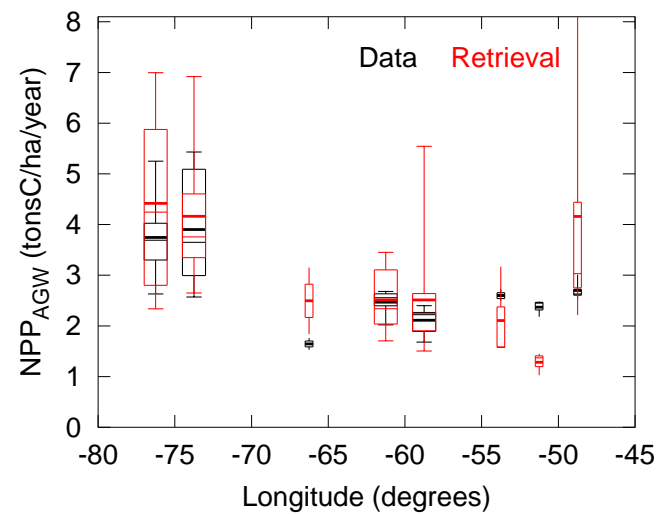

Fig. 7. Impact of introducing $t_{\text {residence }}=f\left(\mathrm{NPP}_{\mathrm{AGW}}\right)$. (a) and (c): AGWB retrieved from ground measurements of $\mathrm{NPP}_{\mathrm{AGW}}$ with $t_{\text {residence }}$ derived from the best fit in Fig. 5. (b) and (d): NPP $\mathrm{AGW}$ retrieved from ground measurements of AGWB with $t_{\text {residence }}$ derived from the best fit in Fig. 5. For panels (a) to (d), we excluded nine points (out of 72) for which annual precipitation were lower than $1500 \mathrm{~mm}$. (c) and (d) show longitudinal gradients of respectively AGWB and $\mathrm{NPP}_{\mathrm{AGW}}$ for sites with latitudes between $10^{\circ} \mathrm{S}$ and $3^{\circ} \mathrm{N}$.

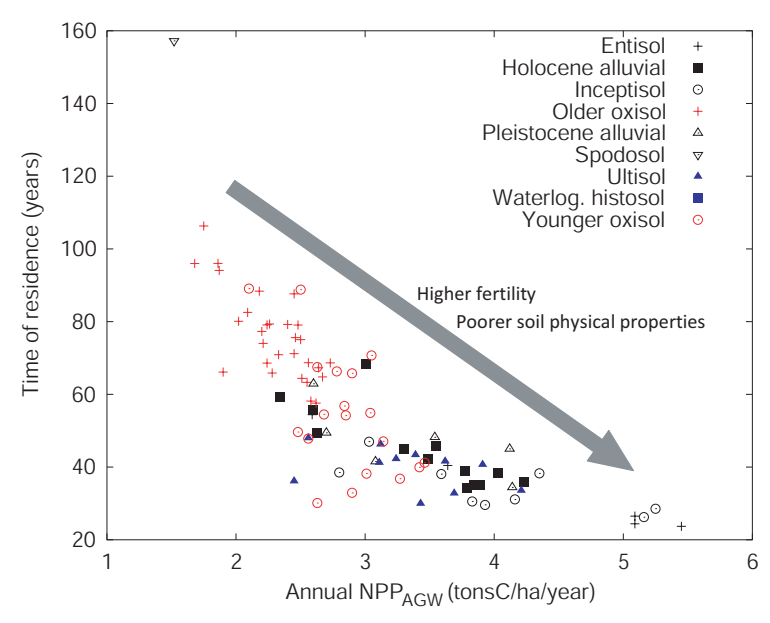

Fig. 8. Time of residence of carbon in wood plotted versus $\mathrm{NPP}_{\mathrm{AGW}}$ (ground measurements from Malhi et al., 2004), for forest stands grouped according to their soil type. The arrow represents an interpretation based on Quesada et al. (2009). regenerating forests. Our results suggest that remote sensing biomass maps would allow rescaling of $\mathrm{NPP}_{\mathrm{AGW}}$ and mortality simulated by a DVM for forests for which there is no visible biomass increment, i.e. for mature undisturbed Amazonian forests, if the accuracy is good enough to discriminate biomass within the $120-180 \mathrm{tC} / \mathrm{ha}$ range. As it will have a spatial resolution of $100 \mathrm{~m}$, satellite biomass measurement may help in inferring intra grid-cell variability in carbon fluxes. Finally, it will allow forcing the initial conditions of DVM simulations under future climatic scenarios.

\section{Appendix A}

\section{Details on the climate dataset}

The two source datasets (CRU and NCEP) overlap between 1948 and 2002, thus the data is processed differently for three periods:

- Between 1948 and 2002 our dataset is based on CRU climatology, and NCEP is then used only to generate the diurnal and daily variability. The NCEP is first 
interpolated to $0.5^{\circ} \times 0.5^{\circ}$ resolution of CRU. CRU provides a cloudiness that is converted to incoming solar radiation based on calculation of clear sky incoming solar radiation as a function of date and latitude of each pixel. Likewise the relative humidity is converted to specific humidity as a function of temperature and surface pressure.

- For years after 2002, we calculate the difference between $M_{\mathrm{x}}-M_{2002}$ where $M_{\mathrm{x}}$ is the mean monthly value for NCEP for year $X$ and $M_{2002}$ the mean monthly value for NCEP for year 2002. Then we add these monthly differences to the CRU 2002 monthly temperature before performing exactly as for the 1948-2002 period.

- For years before 1948, the procedure is the same as for 1948-2002 except that for variability we use data from year 1948 and then the same variability is applied every year.

From CRU data only rainfall, cloudiness, relative humidity and temperature are available. For the others fields (pressure, longwave incoming radiation, windspeed) we directly used the information coming from NCEP re-interpolated on the $0.5^{\circ} \times 0.5^{\circ}$ grid. Before 1948 we took the value from 1948 (hence there is no interannual variability for these fields).

For a complete description of the dataset see http://dods. extra.cea.fr/data/p529viov/cruncep/readme.htm.

Acknowledgements. Many thanks to editor Ulrike Seibt, and to reviewers Rosie Fisher and Chris Huntingford for their useful comments. This study has been co-funded by $1 /$ the Centre National d'Etudes Spatiales/Terre Océan SurfacesContinentales Atmosphère (CNES/TOSCA) program of France in the framework of the preparation of the space mission BIOMASS, and 2/by the European Commission under the EU Seventh Research Framework Programme (grant agreement No. 218795, GEOLAND2). Many thanks to the field scientists involved in collecting the information used in this study, and to Jean-Yves Peterschmitt from LSCE for his help with Python.

Edited by: U. Seibt

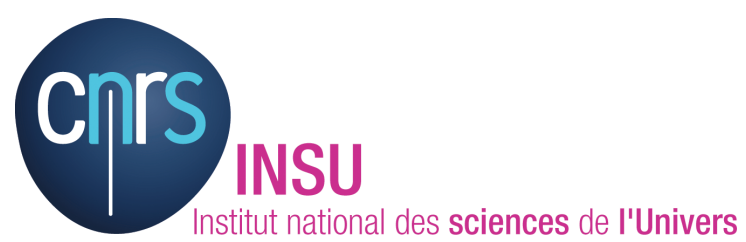

The publication of this article is financed by CNRS-INSU.

\section{References}

Aragão, L. E. O. C., Malhi, Y., Metcalfe, D. B., Silva-Espejo, J. E., Jiménez, E., Navarrete, D., Almeida, S., Costa, A. C. L., Salinas, N., Phillips, O. L., Anderson, L. O., Alvarez, E., Baker, T. R., Goncalvez, P. H., Huamán-Ovalle, J., Mamani-Solórzano, M., Meir, P., Monteagudo, A., Patiño, S., Peñuela, M. C., Prieto, A., Quesada, C. A., Rozas-Dávila, A., Rudas, A., Silva Jr., J. A., and Vásquez, R.: Above- and below-ground net primary productivity across ten Amazonian forests on contrasting soils, Biogeosciences, 6, 2759-2778, doi:10.5194/bg-6-2759-2009, 2009.

Baker, T. R., Phillips, O. L., Malhi, Y., et al.: Variation in wood density determines spatial patterns in Amazonian forest biomass, Global Change Biol., 10, 545-562, 2004.

Chave, J., Condit, R., Muller-Landau, H. C., Thomas, S. C., Ashton, P. S., et al.: Assessing evidence for a pervasive alteration in tropical tree communities, PLoS Biol., 6(3), e45, doi:10.1371/journal.pbio.0060045, 2008.

Chave, J., Navarrete, D., Almeida, S., Álvarez, E., Aragão, L. E. O. C., Bonal, D., Châtelet, P., Silva-Espejo, J. E., Goret, J.-Y., von Hildebrand, P., Jiménez, E., Patiño, S., Peñuela, M. C., Phillips, O. L., Stevenson, P., and Malhi, Y.: Regional and seasonal patterns of litterfall in tropical South America, Biogeosciences, 7, 43-55, doi:10.5194/bg-7-43-2010, 2010.

Chave, J., Andalo, C., Brown, S., Cairns, M. A., Chambers, J. Q., Eamus, D., Folster, H., Fromard, F., Higuchi, N., Kira, T., Lescure, J.-P., Nelson, B. W., Ogawa, H., Puig, H., Riéra, B., and Yamakura, T.: Tree allometry and improved estimation of carbon stocks and balance in tropical forests, Oecologia, 145, 8799, 2005.

Ciais, P., Janssens, I., Shvidenko, A., Wirth, C., Malhi, Y., Grace, J., Schulze, E.-D., Heiman, M., Phillips, O., and Dolman, H.: The potential for rising $\mathrm{CO}_{2}$ to account for the observed uptake of carbon by tropical, temperate, and boreal forest biomes, Chapter 7, in: The Carbon Balance of Forest Biomes, edited by: Griffiths, H. and Jarvis, B. W., Garland Science/BIOS Scientific Publishers, 109-1492004.

Cox, P. M., Betts, R. A., Collins, M., Harris, P. P., Huntingford, C., and Jones, C. D.: Amazonian forest die-back under climatecarbon cycle projections for the, 21 st century, Theor. Appl. Climatol., 78, 137-156, 2004.

Davidson, E., Cláudio, A., Reis de Carvalho, J., Ima, C., Vieira, G., de Ricardo, O., Figueiredo, P., Moutinho, P., Yoko Ishida, F., Primo dos Santos, M. T., Benito Guerrero, J., Kalif, K., and Tuma Sabá, R.: Nitrogen And Phosphorus Limitation Of Biomass Growth, in: A Tropical Secondary Forest, Ecological Applications, Volume 14, Issue sp4 (August 2004) pp. 150163, doi:10.1890/01-6006ESA , 2008: The BIOMASS Mission Report for Assesment, ESA SP 1313/2, 132 pp, ISBN 97892, www.esa.int, last access: November 2008, 2004.

DeFries, R. S., Houghton, R. A., Hansen, M. C., et al.: Carbon emissions from tropical deforestation and regrowth based on satellite observations for the 1980s and 1990s, P. Natl. Acad. Sci., 99, 14256-14261, 2002.

Ducoudré, N. I., Laval, K., and Perrier, A.:, SECHIBA, a new set of parameterizations of the hydrologic exchanges at the landatmosphere interface within the LMD atmospheric general circulation model, J. Climate, 6, 248-273, 1993. 
Friedlingstein, P., Joel, G., Field, C. B., and Fung, I. Y.: Toward an allocation scheme for global terrestrial carbon models, Global Change Biol., 5, 755-770, 1999.

Gibbs, H. K., Brown, S., Niles, J. O., and Foley, J. A.: Monitoring and estimating tropical forest carbon stocks: making REDD a reality, Environ. Res. Lett., 2, 045023, doi:10.1088/17489326/2/4/045023, 2008.

Gloor, M., Phillips, O. L., Lloyd, J. J., et al.: Does the disturbance hypothesis explain the biomass increase in basin-wide Amazon forest plot data?, Global Change Biol., 15(10), 2418-2430, 2009.

Houghton, R. A.: bove ground biomass and the global carbon balance, Global Change Biol., 11, 945-958, 2005.

Houghton, R. A., Lawrence, K. T., Hackler, J. L., and Brown, S.: The spatial distribution of forest biomass in the Brazilian Amazon: a comparison of estimates, Global Change Biol., 7, 731746, 2001.

Huntingford, C., Fisher, R. A., Mercado, L., et al.: Towards quantifying uncertainty in predictions of Amazon "dieback", Philos. T. Roy. Soc. B, 363(1498), 1857-1864, 2008.

IPCC: Climate Change 2007: the Physical Basis, edited by: Solomon, S., Qin, D., Manning, M., Chen, Z., Marquis, M., Averyt, K. B., Tignor, M., and Miller, H. L.: Cambridge University Press, Cambridge UK and New York, NY, USA, 996 pp., 2007.

Jacobson, A. R., Mikaloff Fletcher, S. E., Gruber, N., Sarmiento, J. L., and Gloor, M.: A joint atmosphere-ocean inversion for surface fluxes of carbon dioxide: 2. Regional results, Global Biogeochem. Cy., 21, GB1020, doi:10.1029/2006GB002703, 2007.

Kalnay, E., Kanamitsu, M., Kistler, R., et al.: The NCEP/NCAR 40-year reanalysis project, B. Am. Meteor. Soc., 77, 437-470, 1996.

Keeling, H. and Phillips, O.: The global relationship between forest productivity and biomass, Global Ecol. Biogeogr., 16, 618-631, 2007.

Kesselmeir, J. and Staudt, M.: Biogenic volatile organic compounds (VOC): an overview on emission, physiology and ecology, J. Atmos. Chem., 33, 23-88, 1999.

Körner, C.: Responses of Humid Tropical Trees to Rising $\mathrm{CO}_{2}$, Annu. Rev. Ecol. Evol. S., 40, 61-79, 2009.

Krinner, G., Viovy, N., De Noblet-Ducoudré, N., Ogée, J., Polcher, J., Friedlingstein, P., Ciais, P., Sitch, S., and Prentice, I. C.: A dynamic global vegetation model for studies of the coupled atmosphere-biosphere system, Global Biogeochem Cy, 19, GB1015, doi:10.1029/2003GB002199, 2005.

Le Quéré, C., Raupach, M. R., Canadell, J. G., et al.: Trends in the sources and sinks of carbon dioxide, Nat. Geosci., 2(12), 831836, 2009.

Le Toan, T., Quegan, S., Davidson, M., Balzter, H., Paillou, P., Papathanassiou, K., Plummer, S., Saatchi, S., Shugart, H., and Ulander, L.: The BIOMASS Mission: Mapping global forest biomass to better understand the terrestrial carbon cycle, Remote Sens Environ, accepted, 2010.

Lewis, S. L., Lopez-Gonzalez, G., Sonké, B., et al.: Increasing carbon storage in intact African tropical forests, Nature, 457, 10031007, 2009.

Lewis, S. L., Lloyd, J., Sitch, S., Mitchard, E. T. A., and Laurance, W. F.: Changing Ecology of Tropical Forests: Evidence and Drivers, Annu. Rev. Ecol. Evol. S., 40, 529-549, 2009b.

Malhi, Y. and Grace, J.: Tropical forests and atmospheric carbon dioxide, Trends Ecol. Evol., 15(8), 332-337, 2000.
Malhi, Y., Baker, T. R., Phillips, O. L., et al.: The above-ground coarse wood prod. of 104 Neotrop. forest plots, Global Change Biol., 10, 563-591, 2004.

Malhi, Y., Wood, D., Baker, T. R., et al.: The regional variations of aboveground live biomass in old-growth Amazonian forests, Global Change Biol, 12, 1-32, 2006.

Malhi, Y., Aragão, L. E. O. C., Metcalfe, D. B., et al.: Comprehensive assessment of carbon productivity, allocation and storage in three Amazonian forests, Global Change Biol., 15, 1255-1274, 2009a..

Malhi, Y. Aragão, L. E. O. C., Galbraith, et al.: Exploring the likelihood and mechanism of a climate-change-induced dieback of the Amazon rainforest, P. Natl. Acad. Sci., 106(49), 20610-20615, doi:10.1073/pnas.0804619106, 2009b.

Mitchell, T. D. and Jones, P. D.: An improved method of constructing a database of monthly climate observations and associated high-resolution grids, Int. J. Climatol., 25(6), 693-712, 2005.

Moorcroft, P. R., Hurtt, G. C., and Pacala, S. W.: A method for scaling vegetation dynamics: The ecosystem demography model (ED), Ecol. Monogr., 71(4), 557-585, 2001.

Nepstad, D. C., Tohver, I. M., Ray, D., Moutinho, P., and Cardinot, G.: Mortality Of Large Trees And Lianas Following Experimental Drought In An Amazon Forest, Ecology, 88(9), 2259-2269, 2007.

Phillips, O. L., Baker, T. R., Arroyo, L., et al: Pattern and process in Amazon tree turnover, 1976-2001, Philos. T. Roy. Soc. Lond. B-, 359(1443), 381-407, 2004.

Phillips, O. L., Lewis, S. L., Baker, T. R., et al.: The Changing Amazon Forest, Philos. T. Royal Soc. B, 363, 1819-1827.

Phillips, O. L., Aragão, L. E. O. C., Lewis, S. L., et al.: Drought Sensitivity of the Amazon Rainforest, Science, 323, 1344-1347, 2009.

Quesada, C. A., Lloyd, J., Schwarz, M., Baker, T. R., Phillips, O. L., Patiño, S., Czimczik, C., Hodnett, M. G., Herrera, R., Arneth, A., Lloyd, G., Malhi, Y., Dezzeo, N., Luizão, F. J., Santos, A. J. B., Schmerler, J., Arroyo, L., Silveira, M., Priante Filho, N., Jimenez, E. M., Paiva, R., Vieira, I., Neill, D. A., Silva, N., Peñuela, M. C., Monteagudo, A., Vásquez, R., Prieto, A., Rudas, A., Almeida, S., Higuchi, N., Lezama, A. T., López-González, G., Peacock, J., Fyllas, N. M., Alvarez Dávila, E., Erwin, T., di Fiore, A., Chao, K. J., Honorio, E., Killeen, T., Peña Cruz, A., Pitman, N., Núñez Vargas, P., Salomão, R., Terborgh, J., and Ramírez, H.: Regional and large-scale patterns in Amazon forest structure and function are mediated by variations in soil physical and chemical properties, Biogeosciences Discuss., 6, 39934057, doi:10.5194/bgd-6-3993-2009, 2009.

Quesada, C. A., Lloyd, J., Schwarz, M., Patiño, S., Baker, T. R., Czimczik, C., Fyllas, N. M., Martinelli, L., Nardoto, G. B., Schmerler, J., Santos, A. J. B., Hodnett, M. G., Herrera, R., Luizão, F. J., Arneth, A., Lloyd, G., Dezzeo, N., Hilke, I., Kuhlmann, I., Raessler, M., Brand, W. A., Geilmann, H., Moraes Filho, J. O., Carvalho, F. P., Araujo Filho, R. N., Chaves, J. E., Cruz Junior, O. F., Pimentel, T. P., and Paiva, R.: Variations in chemical and physical properties of Amazon forest soils in relation to their genesis, Biogeosciences, 7, 1515-1541, doi:10.5194/bg-7-15152010, 2010.

Saatchi, S. S., Houghton, R. A., Dos Santos Alvala, R. C., Soares, J. V., and Yu, Y.: Distribution of aboveground live biomass in the Amazon basin, Global Change Biol., 13, 816-837, 2007. 
Sato, H., Itoh, A., and Kohyama, T.: SEIB-DGVM: A new Dynamic Global Vegetation Model using a spatially explicit individualbased approach, Ecol. Model., 200(3-4), 279-307, 2007.

Stephens, B. B., Gurney, K. R., Tans, P. P., et al.: Weak Northern and Strong Tropical Land Carbon Uptake from Vertical Profiles of Atmospheric $\mathrm{CO}_{2}$, Science, 316, 1732-1735, 2007.
Willmott, C. J.: Some comments on the evaluation of model performance, B. Am. Meteorol. Soc., 63(11), 1309-1313, 1982.

Zaelhe, S., Friedlingstein, P., and Friend, A. D.: Terrestrial nitrogen feedbacks may accelerate future climate change, Geophys. Res. Lett., 37, L01401, doi:10.1029/2009GL041345, 2010. 